\title{
4
}

\section{Selective Breakdown of (Ligno)cellulose in lonic Liquids}

\author{
Haibo Xie and Zongbao K. Zhao \\ Dalian National Laboratory for Clean Energy and Dalian Institute of Chemical Physics, \\ CAS, Dalian 116023, \\ PR China
}

\section{Introduction}

(Ligno)cellulose is mainly composed of cellulose, lignin, hemicellulose, and extractives, which represents an abundant carbon-neutral renewable resource. Increasing concerns about global warming and diminishing fossil fuel reserves have stimulated much effort to use (ligno)cellulose as an alternative to petroleum for the production of fuels and chemicals. From a sustainability point of view, shifting society's dependence away from fossil-based energy resources to renewable alternatives can be regarded as an important contribution towards the establishment of sustainable and "Low Carbon" economy for all nations (Ragauskas et al. 2006; Corma et al. 2007). It is estimated that by 2025, up to $30 \%$ of raw materials for the chemical industry will be produced from renewable sources. To achieve this goal, innovative processing technologies, separation and depolymerization processes, as well as catalytic conversion systems are in high demand. In general, it is difficult to dissolve (ligno)cellulose in its native form because of the three-dimensional cross-linked lignin network and strong hydrogen bonds among the polymeric matrix. The inaccessibility of a reliable medium for dissolution of (ligno)cellulose has severely hampered the efficient utilization of lignocellulosic biomass (Kamm 2007).

The emerging ionic liquid-based technologies have paved an environment-friendly and homogenous manner to use (ligno)cellulose. Recent reviews have presented the progresses in bio-materials derived from biopolymers with the ionic liquids platform (Zhu et al. 2006; Pinkert et al. 2009), we thus will not cover this area here. The primary focus of this chapter is to provide an up-to-date overview on the selective breakdown of (ligno)cellulose into platform molecules with catalytic strategies in ionic liquids and to address ongoing in-depth understanding of key issues that bridge the carbohydrates chemistry and petroleum chemistry through ionic liquids. In this regard, those studies on the chemistry of monosaccharides in ionic liquids will be mentioned only if it is essential to clarify some issues related to transformation of (ligno)cellulosic materials.

\section{Dissolution of (ligno)cellulose in ionic liquids}

For a long time, the dissolution and processing of (ligno)cellulose and cellulose are one of the biggest obstacles for their utilization. Rogers et al (Swatloski et al. 2002) reported that imidazolium-based ionic liquids could dissolve cellulose (up to $25 \mathrm{wt} \%$ ), and an amorphous 
cellulose can be produced with addition of anti-solvents (e.g. water, ethanol). Since then, a large library of ionic liquids have been synthesized to develop a more efficient and greener solvent system for dissolution of cellulose (Fukaya et al. 2006; Kilpelainen et al. 2007; Zavrel et al. 2009; Zakrzewska et al. 2010) and lignocellulosic materials (Kilpelainen et al. 2007). Recently, dissolution of cellulose in ionic liquids has been reviewed, and the structures of ionic liquids and their solubility to different types of carbohydrates have been collected (Zakrzewska et al. 2010). Some representative structures of ionic liquids are shown in Figure 1.

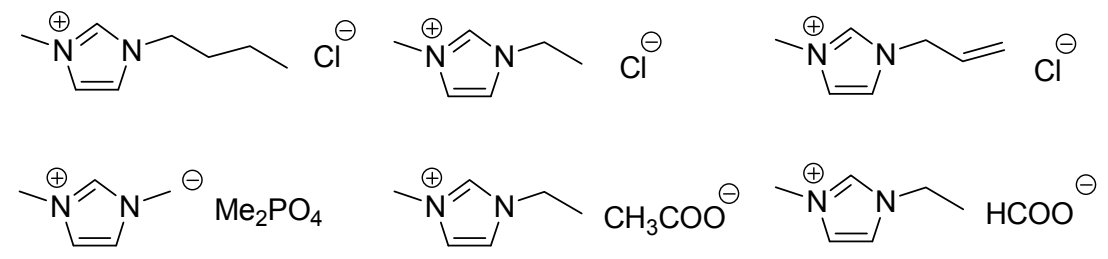

Fig. 1. Representative ionic liquids for biomass dissolution

Despite the increasing number of known ionic liquids capable of dissolving biomass, the mechanism of this dissolution process remains not well understood. There have been a few theoretical and experimental studies, including molecular dynamic studies and NMR analyses. For example, ${ }^{13} \mathrm{C}$ and ${ }^{35 / 37} \mathrm{Cl}$ NMR relaxation measurements have been done for cellulose solution in ionic liquids at varied temperatures and concentrations to investigate the interaction of the chloride ion of the ionic liquids with cellulose, and it was found that the solvation of cellulose by the ionic liquid 1-n-butyl-3-methylimidazolium chloride $\left(\left[\mathrm{C}_{4} \mathrm{mim}\right] \mathrm{Cl}\right)$ involved hydrogen-bonding between the carbohydrate hydroxyl proton and the chloride ion in a 1:1 stoichiometry (Remsing et al. 2006). Further multinuclear NMR spectroscopy experiments demonstrated that the anions in ionic liquids were involved in specific interactions with the solutes, and thus controlled the solvation process (Remsing et al. 2007). On the other hand, the ${ }^{13} \mathrm{C}$ relaxation rate of the imidazolium carbons showed no strong correlation with sugar concentration, regardless of the structure of either the cation or the cellulose, indicating that their role was not essential to the solvation process. Yet, molecular dynamics simulations showed that weak hydrogen bonding interactions with ionic liquids cation occurred through the acidic hydrogen at the $\mathrm{C}(2)$ position on the imidazolium ring (Youngs et al. 2007).

To provide an in-depth rationale for selecting ionic liquids capable of dissolving cellulose, further molecular dynamics simulations with an all-atom force field were performed on a system consisting of 1-ethyl-3-methyl imidazolium acetate ([Emim][OAc]) (Remsing et al. 2008; Liu et al. 2010). Results showed that the interaction energy between the polysaccharide chain and the ionic liquids was stronger (3 times) than that for either water or methanol. In addition to the anion acetate forming strong hydrogen bonds with hydroxyl groups of cellulose, some of the cations were found to be in close contact with the polysaccharides through hydrophobic interactions. It was also observed that the preferred $\beta$-(1,4)-glycosidic linkage conformation of the cellulose was altered when the cellulose was dissolved in [Emim][OAc] as compared to that found in crystalline cellulose dispersed in water. Furthermore, this kind of changes was not reversible during the regeneration process. They hypothesized that this conformational change in the cellulose was one of the key factors in the observed increase in enzymatic hydrolysis rates after ionic liquids pretreatment (Liu et 
al. 2010). Although the fundamental molecular knowledge of these systems elucidated the role of cation during the dissolution process, recently publications of non-imidazolium based ionic liquids demonstrated good solubility to cellulose (Yang et al. 2010), which argued against the key role of anions to a certain extent. Such molecular level knowledge of ionic liquids system should enable the design and rapid computational screening of a wide range of ionic liquids for biomass pretreatment and facilitate the development of new efficient and economic ionic liquids-based biorefinery technologies (Pinkert et al. 2009).

In the traditional petrochemical industry, crude oil is fractionated and refined to produce various grades of liquid transportation fuels, and hydrocarbon feedstocks are functionalized to produce intermediates and specialty chemicals with advanced catalytic strategies (Gallezot 2008; Cheng et al. 2009; Ong et al. 2010). The concept of biorefinery is similar in terms of the utilization of a renewable source of carbon to produce heat, biomaterials, fuels and valueadded chemicals. The overall strategy in the production of hydrocarbon fuels and chemicals from biomass is (1) to de-polymerize biopolymers, (2) to reduce the oxygen content of the parent feedstocks or de-polymerized intermediates and, (3) to create C-C bonds between biomass-derived intermediates to increase the molecular weights of the end products (Alonso et al. 2010). Ionic liquids have been regarded as 'greener' solvents, partially because their properties can be designed through tuning the structures of their constitutive ions (Rogers et al. 2003). The dissolution of (ligno)cellulose in ionic liquids resulted in a full release of all the functional groups and bonds from the well-organized strong hydrogen bonding matrix (Xie et al. 2007; Xie et al. 2009). Thus, biomass dissolved in ionic liquids was more susceptible to chemical attack by external reagents and catalysts. Bearing these in mind, a lot of efforts have been devoted to producing valuable chemicals from biomass via hydrolysis, dehydration, hydrogenolysis, etc., taking the advantages of this new homogenous platform.

\section{Selective breakdown of (ligno)cellulose in ionic liquids}

\subsection{Hydrolysis of (ligno)cellulose}

Hydrolysis of cellulose to fermentable sugars is virtually an essential step in any practical cellulosic biofuel production via a biological route. Furthermore, more chemical processes are seen to convert monosaccharides into fuels and value-added chemicals (Huber et al. 2006; Chheda et al. 2007). Two methods including acid hydrolysis and enzymatic hydrolysis are currently known for biomass hydrolysis. To make cellulosic materials more susceptible to hydrolysis, a pretreatment process is needed to reduce the crystallinity and increase the porosity. Traditional pretreatment technologies using oxidants, organic solvents, lime, or mineral acids, remain imperfect in terms of process greenness and eco- and environmental friendliness (Stephanopoulos 2007). Therefore, the development of advanced pretreatment technologies is one of the main issues in biorefinery. The inherent of dissolution of (ligno)cellulose in ionic liquids provided a new pretreatment technology and an inert homogeneous platform for the hydrolysis of (ligno)cellulose.

\subsubsection{Enzymatic hydrolysis of (ligno)cellulose}

Presently, two types of research have been carried out to hydrolyze the lignocellulose into fermentable sugars in ionic liquids. One is enzymatic hydrolysis of cellulosic materials regenerated from ionic liquids with the addition of an anti-solvent, and the other is in situ enzymatic hydrolysis in ionic liquids. 
Shortly after regeneration of cellulose was demonstrated, efforts have been dedicated to characterizing the regenerated material, finding new applications, and further optimizing the process. It was confirmed that the crystalline structure of cellulose was destroyed (vide ante), which should allow a greater accessibility for the hydrolytic enzymes to rapidly penetrate and hydrolyze the (ligno)cellulose. Liu et al firstly investigated the enzymatic hydrolysis of cellulosic samples that had been pretreated with ionic liquids (Liu et al. 2006). It was found that the hydrolysis rates of wheat straw and steam-exploded wheat straw treated with $\left[\mathrm{C}_{4} \mathrm{mim}\right] \mathrm{Cl}$ were improved significantly. For example, wheat straw samples pretreated with $\left[\mathrm{C}_{4} \mathrm{mim}\right] \mathrm{Cl}$ gave a $70 \%$ conversion, while those pretreated with water had only a $42 \%$ conversion. Further WXRD and morphology study by SEM of the regenerated (ligno)cellulose material showed that diffraction signals from the crystalline regions of spruce sawdust disappeared after the dissolution-regeneration process (Kilpelainen 2007). Those were in an amorphous and porous morphology (Figure 2). For the spruce thermomechanical pulp (TMP) samples regenerated from 1-methyl-3-alkylimidazolium $([\mathrm{Amim}] \mathrm{Cl})$ solution by precipitation upon water addition, glucose yield was $60 \%$ by the enzymatic hydrolysis, while it was only $12 \%$ for the untreated sample.
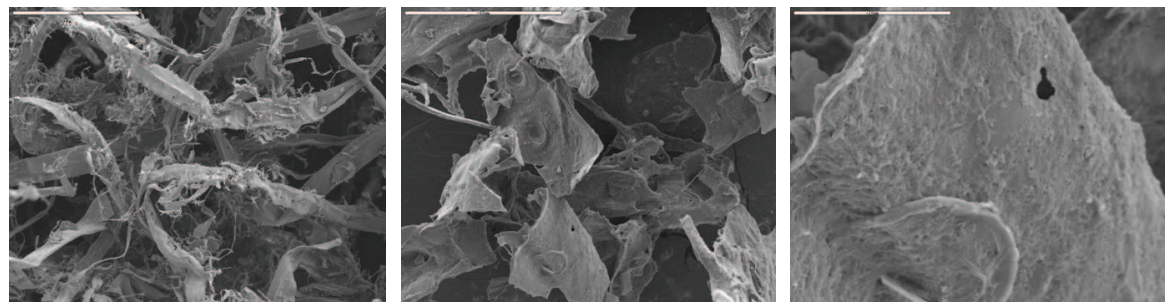

Fig. 2. Morphology study of spruce TMP treated by the ionic liquid [Amim]Cl

As noted earlier, such kinds of crystalline structure and morphology transformation, as well as $\beta$ to a conformational change are anticipated to allow a greater accessibility for the hydrolytic enzymes. An extended research demonstrated an initial clue and potential to produce bioethanol from wheat straw with the ionic liquid pretreatment technology (Li et al. 2009). The fermentability of the enzymatic hydrolysates was evaluated using the yeast Saccharomyces cerevisiae, and the ethanol production was $0.43 \mathrm{~g} / \mathrm{g}$ glucose after $26 \mathrm{~h}$ of fermentation. Results indicated that the pretreatment with the ionic liquid 1-methyl-3ethylimidazolium diethylphosphate ([Emim]DEP) had negligible affects on the downstream ethanol production. The reusability of ionic liquid was also investigated in this study, and the yields of reducing sugars were higher than $52 \%$ even though the ionic liquids were recycled for 5 times. Although biomass pretreatment using ionic liquid is technically attractive, issues about process-costs and the ecological and environmental impacts require further scrutinize.

Recently ionic liquids have also been considered as solvents for biocatalysis (Zhao 2010), and examples of bioreactions in ionic liquids were seen with higher selectivity, faster reaction rate and even greater enzyme stability (Moniruzzaman et al. 2010). It is reasonable to perceive direct enzymatic hydrolysis of cellulose using ionic liquids as the reaction media. However, those conventional cellulose-dissolving ILs are composed of anions such as $\mathrm{Cl}^{-}$, dca-, $\mathrm{HCO}_{2}^{-}$, or $\mathrm{CH}_{3} \mathrm{CO}_{2}$. While these anions facilitate the dissolving of cellulose through the formation of strong hydrogen bonds, they also tend to damage molecular interaction 
networks in a protein leading to denaturation of enzyme. In addition, high viscosity of ionic liquids may also limit the effectiveness of enzymatic transformations. All of these limitations hindered the enzymatic conversion of cellulose in ionic liquids. Therefore, the design and synthesis of ionic liquids capable of dissolving cellulose, and enzyme-compatible, especially compatible with cellulase as well, have been paid much attention to pursue an in situ enzymatic saccharification of cellulose (Zhao 2010). In 2008, Kamiya et al firstly reported their efforts on this topic (Kamiya et al. 2008). They dissolved cellulose sample in the ionic liquid [Emim]DEP, and then mixed the ionic liquid solution with different volumes of citrate buffer $(10 \mathrm{mM}, \mathrm{pH} 5.0)$, followed by the addition of cellulase directly at $40^{\circ} \mathrm{C}$. Little cellulose activity was observed when the volumetric ratio of ionic liquid to water was higher than 3:2. However, decreasing the ratio enhanced enzymatic activity remarkably, and a reducing sugar yield over $70 \%$ (composed of $50 \%$ glucose $+20 \%$ cellobiose) was achieved after $24 \mathrm{~h}$ when the ionic liquid to water ratio was 1:4. Importantly, glucose formation in the aqueous-ionic liquid mixture was approximately 2 -fold more than that of the aqueous system under identical conditions, indicating that the ionic liquid was truly enzyme-compatible. In comparison, when the ionic liquid [Emim][OAc] was applied under these conditions, cellulase activity was only approximately half of that with [Emim]DEP, suggesting that the anion structure played a key role in terms of the cellulase activity in ionic liquids.

The activity and stability of a commercial cellulase samples in eight ionic liquids have been investigated by optical and calorimetric techniques to gain further insights into the in situ enzymatic saccharification process (Bose et al. 2010). Some important issues concerning the cellulase in ionic liquids have been elucidated. Among those ionic liquids, hydrolysis was observed only in 1-hydrogen-3-methylimidazolium chloride and tris-(2-hydroxyethyl) methyl ammonium methylsulfate (HEMA). Interestingly, hydrolysis at $65^{\circ} \mathrm{C}$ had a higher initial rate but reached a plateau after $2 \mathrm{~h}$ in the aqueous buffer, whereas the reaction in these two ionic liquids proceeded with a lower initial rate but went monotonically over time. Further investigation of relationship of enzymatic activity and thermal stability with viscosity and reaction temperature demonstrated that this difference in the rate of hydrolysis was largely attributed to two factors, the higher viscosity of the ionic liquids and enzyme stability. The inherent high viscosity of the ionic liquids was a retarding factor for the enzymatic hydrolysis, since it slowed the diffusion of the enzyme to its substrate resulting in a lower observed activity. Reversibility of the unfolding process was studied by gradual cooling of the denatured enzyme from temperature higher than the $T_{1 / 2}$. It was found that cellulase unfolding was irreversible in buffer and accompanied by precipitation of the enzyme. In HEMA, folding and unfolding processes were reversible even at up to $120^{\circ} \mathrm{C}$, which indicated that excellent cellulase thermo stability can be achieved in particular ionic liquids. However, in 1-hydrogen-3-methylimidazolium chloride, the unfolding process was completely irreversible. The potential of enzymatic saccharification process based on ionic liquids technology can be envisioned, however, it remains challenging to design an ionic liquid that compromises these opposing properties of dissolving cellulose, retaining the activity of the enzymes, yet having a low viscosity. From an eco- and environment-friendly point of view, efforts should be put on reducing operation costs and synthesis of novel ionic liquids.

\subsubsection{Acid hydrolysis of (ligno)cellulose}

Many attempts to hydrolyze cellulose into fermentable sugars catalyzed by mineral acids have been reported. These processes were usually done under heterogeneous and harsh 
conditions in which the (ligno)cellulose raw material was typically not solubilized in the reaction medium. Thus, the supramolecular and crystalline structure of cellulose imposed important restrictions on the kinetics of the hydrolysis. Consequently, traditional acid hydrolysis of (ligno)cellulose was inefficient and cost-intensive. Noting that the full dissolution of cellulose in ionic liquids could break internal and external supramolecular structures among the cellulosic fibers, and we envisioned that it should provide an opportunity to revisit the acid-catalyzed hydrolysis technology. In 2007, we firstly reported the hydrolysis behavior of cellulose in ionic liquids in the presence of mineral acids (Li and Zhao 2007). It was interesting to find that catalytic amounts of acid were sufficient to drive the hydrolysis reaction. For example, when the acid/cellulose mass ratio was set to 0.46 , yields of total reducing sugar (TRS) and glucose were $64 \%$ and $36 \%$, respectively, after 42 min at $100{ }^{\circ} \mathrm{C}$. In fact, excess acid loading in the ionic liquid system was detrimental in terms of sugar yields because side reaction tended to occur that consumed the hydrolysis products. Preliminary kinetic study indicated that the cellulose hydrolysis catalyzed by $\mathrm{H}_{2} \mathrm{SO}_{4}$ followed a consecutive first-order reaction sequence, where $k_{1}$ for TRS formation and $k_{2}$ for TRS degradation were $0.073 \mathrm{~min}^{-1}$ and $0.007 \mathrm{~min}^{-1}$, respectively. Our further study on the hydrolysis behavior of (ligno)cellulose in ionic liquids demonstrated that hydrochloric acid was also an effective catalyst (Li et al. 2008). TRS yields were up to 66\%, 74\%, 81\% and $68 \%$ for hydrolysis of corn stalk, rice straw, pine wood and bagasse, respectively, in the presence of only $7 \mathrm{wt} \%$ catalyst at $100{ }^{\circ} \mathrm{C}$ under an atmospheric pressure within $60 \mathrm{~min}$. Under those conditions, the constants for $k_{1}$ and $k_{2}$ were $0.068 \mathrm{~min}^{-1}$ and $0.007 \mathrm{~min}^{-1}$, respectively, for the hydrolysis of corn stalk.

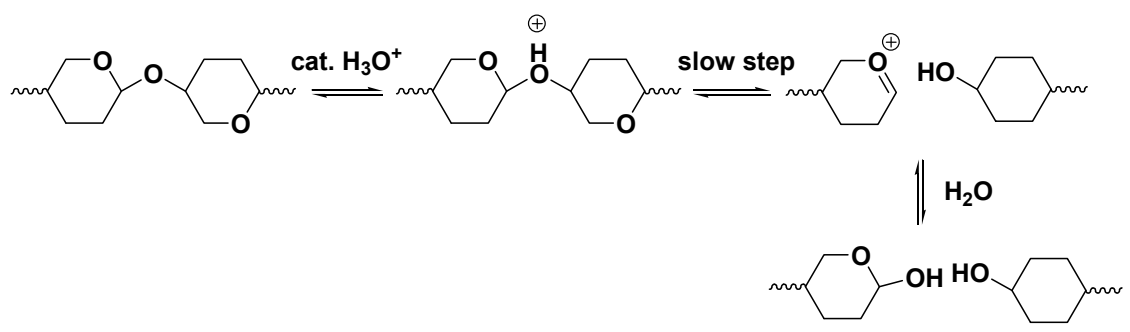

Fig. 3. Proposed mechanism for hydrolysis of cellulose. Hydrogen, hydroxyl, and hydroxymethyl groups are omitted for better clarity (Adopted from the reference (Rinaldi et al. 2010)).

Further study showed that the rates of these two competing reactions varied with acid strength and that for acids with an aqueous pKa below zero $(\mathrm{Ka}<1)$, and the hydrolysis reaction was significantly faster than the degradation of glucose, thus allowing hydrolysis to be performed with a high selectivity in glucose (Vanoye et al. 2009). Although the acidity in ionic liquids is a concept still in its infancy, the relative acidity order of several organic and inorganic acids in ionic liquids was found identical to that in water (MacFarlane et al. 2006). The proposed hydrolysis of cellulose usually consists of three consecutive processes, (1) protonation of the glycosidic oxygen; (2) formation of a cyclic carbocation; (3) nucleophilic attack on the cyclic carbocation species by a water molecule (Figure 3). Although the second one is the rate-limiting step, the protonation of the glycosidic oxygen is difficult in some electron deficient acetals on the basicity of the acetal O-site and the hydroxyl O-sites and the acidic strength. Therefore, although some ionic liquids containing weak basic anions (e.g. 
acetate, organophosphates) are capable of dissolving cellulose, they are not good solvents for hydrolysis of cellulose, because a relative weak acid formed by addition of a strong acidic catalyst (Rinaldi et al., 2010).

A recent work on pretreatment of wood species in ionic liquids in the presence of mineral acids suggested that a significant amount of lignin was also degraded, together with hydrolysis of cellulose and hemicellulose ( $\mathrm{Li}$ et al. 2010). This was based on the results of GC-MS and 31P NMR analysis of the ethyl acetate extracted samples produced during the pretreatment process. In fact, authors demonstrated the presence of compounds such as 5hydroxymethylfurfural, furan-2-carboxylic acid, catechol, methylcatechol, methylguaiacol, acetoguaiacone, and acetol, among which those phenolic compounds and acetol should be originated from lignin.

The facts that the higher the degree of polymerization (DP) value of cellulose, the longer was the reaction time required for a satisfactory glucose yield, and that the longer reaction time favored glucose formation, while the shorter reaction time produced more TRS, implied that cellulose hydrolysis in ionic liquids catalyzed by mineral acids most likely followed a random hydrolysis mechanism, as observed with the concentrated acid system ( $\mathrm{Li}$ et al. 2007). During the hydrolysis process, both endoglycosidic and exoglycosidic scission occurred, but the endoglycosidic product, oligoglucoses, was the major one in the initial stage, which usually was observed in traditional heterogeneous hydrolytic systems. Such phenomena were later confirmed in the study of solid acid (Amberlyst 15DRY) catalyzed hydrolysis of cellulose and (ligno)cellulose in ionic liquids (Rinaldi et al. 2008; Rinaldi et al. 2010). In those studies, depolymerized cellulose was precipitated and recovered by addition of water to the hydrolytic system, and the DP value was estimated by gel-permeation chromatography. It was found that the size of recovered cellulose fibers became successively smaller over time, resulting in a colloidal dispersion for the material recovered after $5 \mathrm{~h}$. The depolymerization of cellulose proceeded progressively, resulting in the formation of soluble oligosaccharides if the reaction was carried out over a long time. For example, cellooligomers consisted of approximately ten anhydroglucose units (AGU) were seen after $5 \mathrm{~h}$.

There is an intriguing question in the case of hydrolysis of cellulose catalyzed by solid acids in ionic liquids, where does the hydrolysis reaction take place, on the catalyst surface or in the bulk solution? The observation of induction period for the production of glucose and titration results of the ionic liquids separated from a suspension of Amberlyst 15DRY in [Bmim] $\mathrm{Cl}$ suggested that proton was progressively released into the bulk liquid within an hour upon through an ion-exchange process involving [Bmim] ${ }^{+}$of the ionic liquid and $\mathrm{H}^{+}$ species of the solid acid. The true catalytic species in the case of Amberlyst 15DRY-catalyzed hydrolysis was the released $\mathrm{H}^{+}$species, and an activation process by washing it with a $\mathrm{H}_{2} \mathrm{SO}_{4}$ solution is required for the reuse of this solid catalyst (Rinaldi et al. 2010).

A full depolymerization of cellulose into fermentable sugar or other derivatives in ionic liquids challenges separation technology, because those ionic liquids per se are excellent solvents for monosaccharides, polar, water soluble and unstable under high temperature. Up to now, an efficient and economic method has not been achieved (Binder and Raines 2010; Brennan et al. 2010), which maybe the severe barrier of the ionic liquids based technologies for a practical use point of view. In this regard, the controlled depolymerization of cellulose into water insoluble oligosaccharides followed by an enzymatic hydrolysis seemed the most interesting transformation. For example, cellooligomers with a DP value around 30 were precipitated in $90 \%$ yield by the addition of water after microcrystalline cellulose was hydrolyzed in ionic liquids for $1.5 \mathrm{~h}$. Another general strategy is to use ionic liquids as pretreatment agents to 
facilitate the hydrolysis process (vide ante). For example, pretreatment of cellulose with [Bmim] Cl led to loosen crystalline cellulose through partial transformation of cellulose I to cellulose II, which could facilitate the attack of proton during the subsequent hydrolysis over Nafion NR50 (Kim et al. 2010).

Other acids, such as trifluoroacetic acid, Brönsted acid ionic liquids, have also been used and satisfactory results were obtained in hydrolysis of cellulose in ionic liquids (Amarasekara and Owereh 2009; Amarasekara and Owereh 2010). In 2010, a more environment-friendly process was reported for biomass conversion in ionic liquid-water mixture (Zhang et al. 2010). Under relatively mild conditions $\left(\leq 140{ }^{\circ} \mathrm{C}, 1 \mathrm{~atm}\right)$ and in the absence of acid catalysts typically employed in biomass conversion, the dissolved cellulose in [Emim] $\mathrm{Cl}$ can be converted into reducing sugars in up to $97 \%$ yield. The combined study of experimental methods and ab initio calculations demonstrated the $K w$ value of water in the mixture was up to 3 orders of magnitude higher than the pure water under ambient conditions. Such high $K w$ values are typically achievable under high temperature or subcritical conditions, which is responsible for the remarkable performance without adding acid catalysts. They hypothesized that the increased $\left[\mathrm{H}^{+}\right]$was due to the enhanced water auto ionization by ionic liquids. This process will be affected by the electrostatic environment of the solution, the broad dielectric medium of the solvent and the temperature. Comparative ab initio calculations based on the thermodynamic cycle showed that IL-water mixture exhibited higher concentrations of both $\left[\mathrm{H}^{+}\right]$and $\left[\mathrm{OH}^{-}\right]$than pure water, thus enabling the acid- and base-catalyzed reactions.

\subsection{Catalytic conversion of (ligno)cellulose into furfurals}

Given the chemical differences between biomass feedstocks and conventional fuels and chemicals, biomass should obviously be subjected to deoxygenation/dehydration in order to reduce the oxygen content. A desired intermediate derived from biomass, usually referred as platform molecules, should afford a great degree of flexibility in downstream processes and applications (Alonso et al. 2010). In 2004, the National Renewable Energy Laboratory proposed twelve building block chemicals that can be readily produced from sugars via biological or chemical transformations (Werpy and Petersen 2004). These twelve building blocks can be subsequently converted into a number of high-value chemicals or bulky materials. Among them, 5-hydroxymethylfurfural (HMF), is recognized as a versatile intermediate in biofuel chemistry and the petroleum industry (Figure 4). Production of HMF from fructose by dehydration is relatively easy. Although various conditions were published for this transformation, we will not discuss it. Instead, we will focus on production of HMF from cellulose and lignocellulosic materials. We also cover a few examples where HMF was produced using glucose because it had a tight connection to our main focus.

Although there were early studies on HMF production using glucose as the feedstock, yields were not appreciable. In 2007, a system of metal chloride in ionic liquids was introduced to convert glucose into HMF (Zhao et al. 2007). Specifically, a record high yield of $68 \%$ was achieved in the presence of $\mathrm{CrCl}_{2}$ in [Emim] Cl. It was proposed that glucose was isomerized through a $\mathrm{CrCl}_{2}$-associated enediol intermediate to fructose followed by dehydration reaction. It was interesting to note that an addition of strong ligands, 2,2'bipyridine or glyceraldehydes, essentially shut down the reaction: HMF was receive in less than $2 \%$ yield in the presence of 2,2'-bipyridine. The authors concluded that the metal catalyst interacted with the hemiacetal portion of glucopyranose, and that there was little 
interaction with polyalcohol portion of the sugar. The authors also proposed that the $\mathrm{CrCl}_{3}$ anion played an important role in proton transfer, facilitating mutarotation of glucose to fructose.

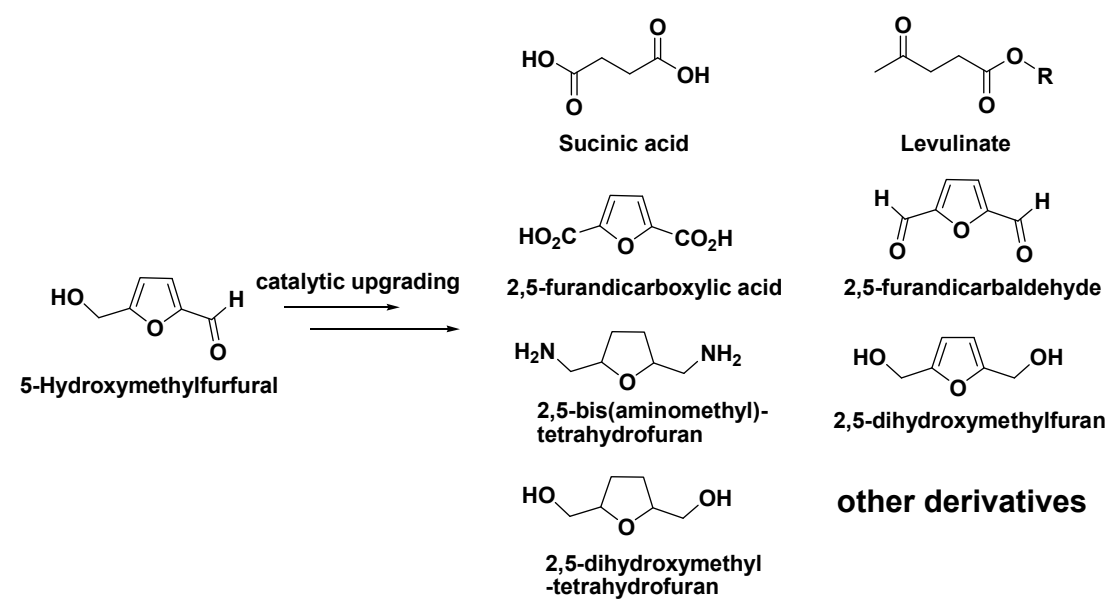

Fig. 4. Versatile derivatization of 5-hydroxymethyl furfural

Given these advancements on production of HMF from monosaccharides, the direct conversion the most abundant of cellulose and (ligno)cellulose into HMF remains challenging. We were the pioneer in the direct transformation of cellulose and (ligno)cellulose into furans ( $\mathrm{Li}$ 2008). We demonstrated that $\mathrm{CrCl}_{3}$ in ionic liquid was an outstanding system for HMF production from cellulose under microwave irradiation conditions. Thus, treatment of Avicel cellulose $(100 \mathrm{mg})$ and $\mathrm{CrCl}_{3} \cdot 6 \mathrm{H}_{2} \mathrm{O}(10 \mathrm{mg})$ in $\left[\mathrm{C}_{4} \mathrm{mim}\right] \mathrm{Cl}(2.0 \mathrm{~g})$ under microwave irradiation $(400 \mathrm{~W})$ for 2 min gave $\mathrm{HMF}$ in $62 \%$ yield ( $\mathrm{Li}$ et al. 2009). Interestingly, when these components were heated at $100{ }^{\circ} \mathrm{C}$ over an oil-bath for $240 \mathrm{~min}$, HMF yield was only $17 \%$, but TRS yield was $45 \%$. These results suggested that microwave irradiation was the key to high yields of $\mathrm{HMF}$ and $\mathrm{CrCl}_{3} \cdot 6 \mathrm{H}_{2} \mathrm{O}$ was capable of catalyzing hydrolysis of cellulose. It should also mention that this system afforded HMF in over $90 \%$ yield when glucose was employed. Following up this work, we also demonstrated that furans production under similar conditions using biomass as the feedstocks (Zhang et al. 2010). Corn stalk, rice straw and pine wood treated under typical reaction conditions produced HMF and furfural in yields of $45-52 \%$ and $23-31 \%$, respectively, within $3 \mathrm{~min}$. In a separate study, a pair of metal chlorides $\left(\mathrm{CuCl}_{2}\right.$ and $\left.\mathrm{CrCl}_{2}\right)$ was used as the catalysts for direct conversion of cellulose into HMF in [Emim] Cl under mild conditions ( $\mathrm{Su}$ et al. 2009). For example, HMF yields were around $55 \%$ when the reactions were held at $80-120^{\circ} \mathrm{C}$ for 8 $\mathrm{h}$ in the presence of the paired catalyst $\mathrm{CuCl}_{2} / \mathrm{CrCl}_{2}\left(\mathrm{X}_{\mathrm{CuCl} 2}=0.17\right)$. Authors also demonstrated that the catalytic performance of recovered [Emim] $\mathrm{Cl}$ and the catalysts was maintained in repeated uses once the reaction was done in an extractive separation manor using methylisobutylketone as the extracting agent. It was interesting to note that single metal chlorides at the same total loading showed considerably less activity under similar conditions. This results were in sharp contrast to our work where high HMF yield was achieved using $\mathrm{CrCl}_{3} \cdot 6 \mathrm{H}_{2} \mathrm{O}$ along as the catalyst ( $\mathrm{Li}$ et al. 2009). 
In parallel, chemical transformation of lignocellulosic biomass into furans in the DMA/ionic liquids mixture catalyzed by acid catalysts was also developed (Binder and Raines 2009). In this system, the ionic liquids were used as additives. A broad range of substrates including cellulose and (ligno)cellulose were tested, and good results were achievable. For example, in the case of cellulose, $\mathrm{HMF}$ yield was $22 \%$ in the DMA/ $\mathrm{LiCl}-\mathrm{HCl}$ system in the presence of $\mathrm{CrCl}_{2}$, while the yield reached $54 \%$ if ionic liquids were added to $60 \mathrm{wt} \%$ concentration. Interestingly, a mineral acid was required to hydrolyze the cellulose into glucose for a satisfactory HMF yield in this mixed solvent system, while in the pure ionic liquid system, $\mathrm{CrCl}_{2}$ acted as a catalyst both for the hydrolysis process and for the muturonation and dehydration processes. In 2010, conversion of cellulose into HMF in up to $89 \%$ yield was reported using $\mathrm{CrCl}_{2}$ as a co-catalyst in [Emim]Cl-water mixture under relatively mild conditions $\left(\leq 140^{\circ} \mathrm{C}, 1 \mathrm{~atm}\right)$ (Zhang et al. 2010).

Given the significant achievements in the conversion hexoses into HMF in ionic liquid in the presence of metal chlorides, in-depth information is still needed for a creditable mechanism. Back to 1970s, the conversion of glucose into HMF in acidic water was studied (Harris and Feather 1974; Harris and Feather 1975; Farber et al. 1989). Although the yields were low, mechanistic insights were collected from isotopic labeling experiments. It was believed that an 1,2-hydride shift was a major contributor in the process of formation of fructose and HMF from glucose. Inspired by the enzyme-catalyzed process, in which the initial proton transfer is catalyzed by a basic residue (His53) located in the cavity of the enzyme active site, Pidko and co-workers reported the molecular-level details of the unique reactivity of chromium (II) chloride towards selective glucose dehydration in ionic liquids through combining kinetic experiments, in situ X-ray absorption spectroscopy and density functional theory calculations (Pidko et al. 2010). They proposed that the chloride anions of the ionic liquids play the role of basic mediators upon formation of a hydrogen-bonding network with the hydroxyl groups of the carbohydrate, thus facilitating the proton transfer; the ratelimiting H-shift reaction of the open form of the carbohydrate is facilitated by the transient self-organization of the Lewis acidic $\mathrm{Cr}^{2+}$ centers into a binuclear complex. This research provided a primary cooperative nature of the $\mathrm{Cr}$ complexes and the presence of moderately basic sites in the ionic liquids.

Accordingly, two variations for the mechanism were proposed recently (Binder and Raines 2009; Binder and Raines 2010). The enolization pathway that goes through an enediol(ate) intermediate that is protonated at C-1 to yield a ketose assisted by $\mathrm{Cr}^{2+}$, which is dehydrated into HMF via a furanosyl oxocarbenium ion. The hydride shift pathway that goes through a chromium assisted 1,2-hydride shift to form the ketose from the aldose in a single step. Their further study using isotopic labeled glucose demonstrated the ketose formation occurring via 1,2-hydride shift, similar to that found in the catalytic mechanism of xylose isomerase. We considered that both in these two pathways, the cooperative action of $\mathrm{Cr}^{2+}$ and halide anion contributed the formation of the enediol intermediate and the 1,2-hydride shift to form ketose from aldose. Collectively, a putative mechanism for the chromiumcatalyzed conversion of glucose into HMF was presented in Figure 5. It is worthy to mention that although $\mathrm{CrCl}_{2}$ has been very successful in terms of $\mathrm{HMF}$ production from glucose and cellulose, $\mathrm{CrCl}_{3}$ or $\mathrm{CrBr}_{3}$ gave similar, even better results for the same chemistry (Binder and Raines 2009; Li et al. 2009; Binder and Raines 2010). We believe that the good performance of $\mathrm{CrCl}_{2}$ might be due to the oxidation of $\mathrm{CrCl}_{2}$ into $\mathrm{CrCl}_{3}$ by residual oxygen in the reaction system. Apart from the metal catalysts for the efficient conversion of glucose into HMF in ionic liquids, heteropoly acids were also very efficient for the dehydration of glucose to 
HMF, particularly in the presence of acetonitrile as a cosolvent (Chidambaram and Bell 2010). For example, a glucose conversion of $98 \%$ with a HMF selectivity of $99 \%$ can be achieved using 12-molybdophosphoric acid (12-MPA) as a catalyst in [Emim]Cl and acetonitrile after $3 \mathrm{~h}$ at $393 \mathrm{~K}$. The authors proposed that the high selectivity was ascribed to the stabilization of the 1,2-enediol and other intermediates involved in the dehydration of glucose, the avoidance of the 2,3-endiol intermediate leading to furylhydroxymethyl ketone and the suppression of the formation of humans from glucose by the added acetonitrile.

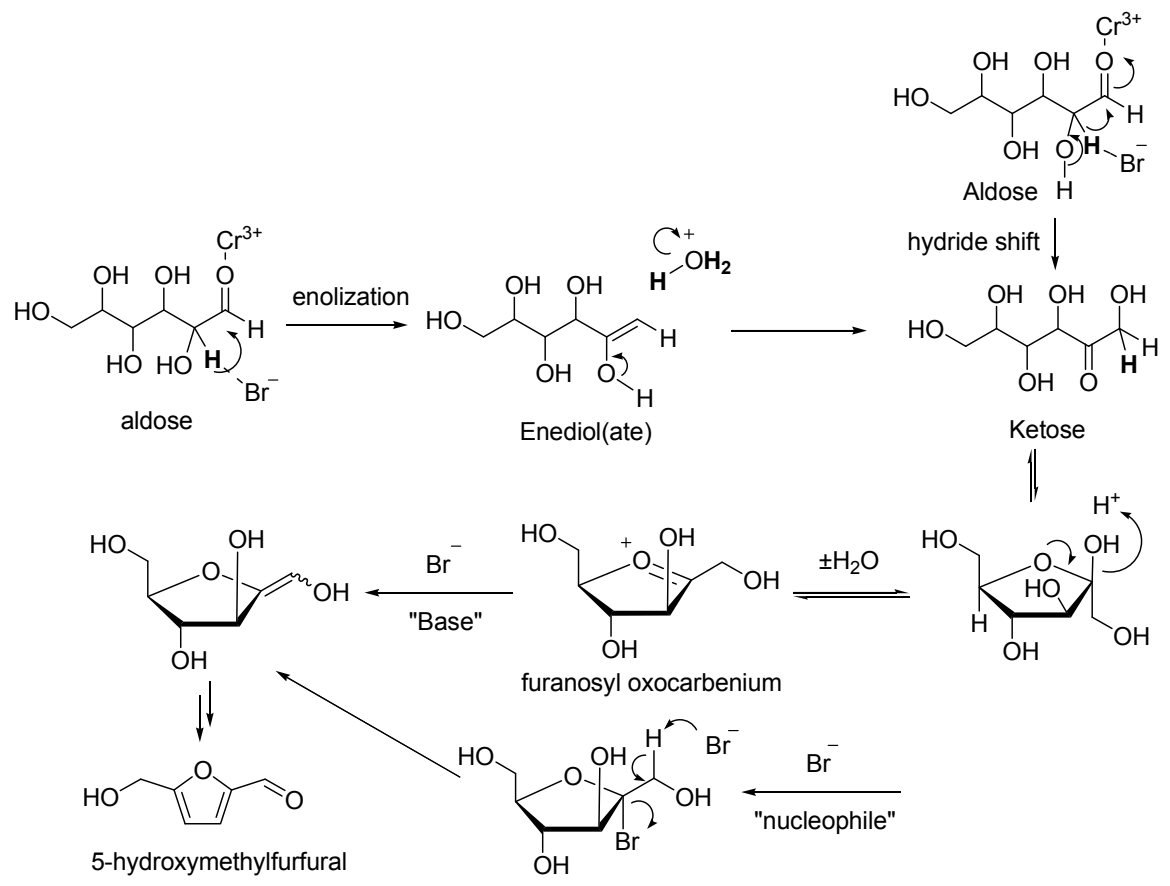

Fig. 5. Possible mechanisms for the dehydration of glucose into HMF in the case of bromide based ionic liquids in the presence of $\mathrm{Cr}^{2+}$ (Formulated and improved from that in references (Binder and Raines 2009; Binder and Raines 2010)).

\subsection{Reactions leading to miscellaneous products}

As expected, a successful lignocellulosic biorefinery can be realized through a combination of different catalytic technologies and biomass processing strategies in ionic liquids for the flexible production of fuels, chemicals and materials (Ragauskas et al. 2006; Corma et al. 2007; Gallezot 2008; Alonso et al. 2010). Sugar alcohols, a family of important bioproducts, are usually produced from the hydrogenation of monosaccharides. Given that cellulose can be dissolved in ionic liquids, it is logical to develop processes for direct hydrogenolysis of cellulose into sugar alcohols. Reductive depolymerization of cellulose was recently reported in the presence of hydrogen gas catalyzed by the combination of a heterogeneous metal catalyst and a homogeneous ruthenium catalyst (Ignatyev et al. 2010). Authors began their study with the hydrogenation of 1,1-diethoxycyclohexane using a combination of the heterogeneous catalysts $\mathrm{Rh} / \mathrm{C}$ and $\mathrm{Pt} / \mathrm{C}$ in the presence of Lewis acid $\mathrm{BF}_{3} \cdot \mathrm{Et}_{2} \mathrm{O}$ at $20{ }^{\circ} \mathrm{C}$ 
under 2 MPa hydrogen gas, and ethoxycyclohexane was obtained in $100 \%$ yield. Further study found that the catalytic system was not effective for the hydrogenation of cellobiose. However, a much better result, $43 \%$ yield of sorbitol was obtained when the heterogeneous catalysts were replaced by a homogeneous catalyst precursor $\left(\mathrm{HRuCl}(\mathrm{CO})\left(\mathrm{PPh}_{3}\right)_{3}\right)$. Under optimized conditions, sorbitol yield was $51 \%$ using cellulose as the feedstock. Additional control experiments confirmed that each component of the catalytic mixture, such as hydrogen, $\mathrm{HRuCl}(\mathrm{CO})\left(\mathrm{PPh}_{3}\right)_{3}, \mathrm{Pt} / \mathrm{C}$, and water, was necessary for the reaction and that the role of the ruthenium complex was to act as a hydrogen transport agent in the ionic liquids via formation of hydride compounds, thus supplying $\mathrm{Pt} / \mathrm{C}$ catalyst with hydrogen.

Transition metal nanoparticles as catalysts for organic transformation has been received extensively attention due to their superior catalytic activities and selectivity relative to their corresponding bulk catalytic materials (Johnson 2003). It is generally received that their small particle size and high surface structure dominated their better performance. Zhu and co-workers (Zhu et al. 2010) designed an ionic liquid capable reversible binding cellulose with the consideration of the ability to stabilize transition metal nanoparticles and the reversible reaction of a boronic acid with sugars (Figure 6). They anticipated that boronic acids could break up the crystal packing of cellulose by reversible binding with the multiple hydroxyl groups, thereby improving solubility and catalytic activity. It was found that in the absence of the designed ionic liquids, a $15 \%$ conversion was achieved for cellulose hydrogenation to hexitols using a $\mathrm{Ru}$ nanocluster catalyst in [Bmim] Cl. However, the cellulose can be successfully converted into hexitols in high yields ranging from $76 \%$ to $93 \%$. It is also interesting to find that cellulose was smoothly hydrolyzed to glucose using the designed ionic liquids with a $95 \%$ yield after $5 \mathrm{~h}$ at $80{ }^{\circ} \mathrm{C}$. Furthermore, the nanoparticle catalyst was easily recovered from the reaction mixture, and the activity was maintained after 5 runs. Further study by ${ }^{11} \mathrm{~B}$ NMR supported the complex formations between the ionic liquid with cellulose, which facilitated the solubilization of cellulose.

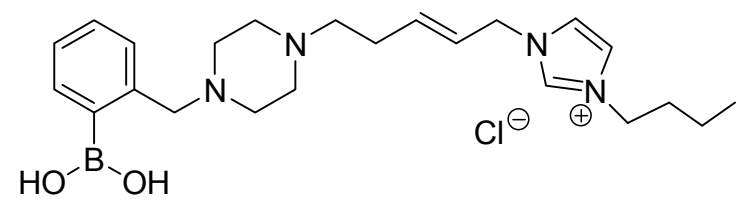

Fig. 6. Boronic acid functionalized ionic liquids

Long-chain alkyl glycosides are no-ionic compounds with excellent surfactant properties, low toxicity and good biodegradability. They have a couple of applications as cosmetics and detergents, food emulsifiers and pharmaceutical dispersing agents. One-pot catalytic conversion of cellulose into biodegradable surfactants was reported in ionic liquids under mild conditions (Villandier and Corma 2010). It was found that a sulfuric resin can catalyze a direct conversion of cellulose into alkyl glucosides with mass yields up to $82 \%$ (Figure 7). A lot of alcohols including butanol, hexanol, and octanol were used in the study, and total yields of surfactants were ranged from $7.2 \%$ to $91 \%$. The amount of water in the reaction medium played an important role. During the hydrolysis process, water was a reactant inhibiting the formation of HMF as well as hemiacetals between the aldehyde group of the monosaccharide and the alcohols. They found that a removal of water from the system by reducing the reaction pressure could facilitate the glycosidation significantly. 
A very similar work was also reported where cellulose was converted into the related alkyl glycosides in [Bmim] Cl in the presence of an acidic resin Amberlyst 15DRY (Ignatyev et al. 2010).<smiles>OC1CO[C@H](O)[C@@H](O)[C@H](O)C1O</smiles><smiles>OC1COC2(O)OC1C(O)C(O)C2O</smiles>

Alkyl- $\alpha, \beta$-glucopyranoside

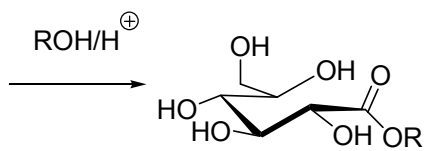

Hemiacetal<smiles>[R]OC1C(O)C2OC1C(O)C2CO</smiles>

Alkyl- $\alpha, \beta-$-glucofuranoside

Fig. 7. Conversion of glucose into alkyl-a, $\beta$-glycoside surfactants

\subsection{Greener pathways for the conversion of (ligno)cellulose in ionic liquids}

The development of a sustainable chemical industry requires sustainable raw materials and technologies for the conversion of raw materials into end products. The design of a "green" compound or 'green' technology, whether the role is as a solvent, reagent or catalyst should ideally address issues such as low toxicity and ready biodegradability without the generation of toxic, persistent metabolites (Kamm 2007). The conversion of biomass into value-added chemicals with the ionic liquids platform already have met two of the 12 green chemistry principles, using green solvents and biorenewable resources as raw materials. With more studies in this field, researchers are also realizing the potential problems, such as potential biotoxicity of ionic liquids, low biodegradability, cost-intensive separation process and energy consumption (Coleman 2010; Thi et al. 2010). With the development of green technology and green chemistry, researchers are also introducing new technologies and concepts into this field (Anastas and Zimmerman 2003) (Figure 8).

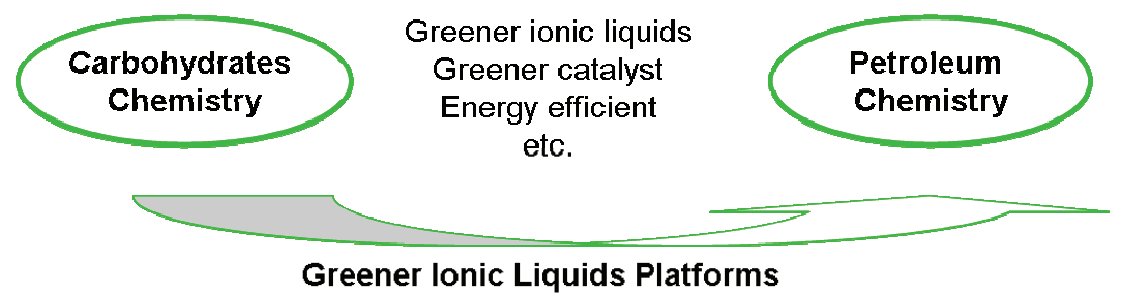

Fig. 8. Greener pathways for the conversion of (ligno)cellulose in ionic liquids

Microwave irradiation is regarded as a more energy efficient heating method and it has been widely used in organic synthesis. In 2009, we demonstrated that microwave irradiation could drastically improve the $\mathrm{CrCl}_{3}$-catalyzed $\mathrm{HMF}$ production form cellulose in ionic liquids ( $\mathrm{Li}$ et al. 2009). In fact, ionic liquids have excellent dielectric properties which can facilitate the energy transformation to heat the reaction rapidly, volumetrically and 
simultaneously. Other microwave effects, such as lowering activation energy or increasing the preexponential factor in the Arrhenius law due to orientation effect of polar species in an electromagnetic field might also contributed.

With increasing concerns about the environmental effects, the design, synthesis and application of low toxic and biodegradable ionic liquids have been obtained much attention. In this regard, some renewable materials-based ionic liquids have been prepared to investigate their effectiveness in the conversion of fructose into HMF ( $\mathrm{Hu}$ et al. 2008; Hu et al. 2009). Some ionic liquids prepared entirely from cheap and renewable materials, such as $\mathrm{ChoCl} /$ malonic acid, $\mathrm{ChoCl} /$ oxalic acid and $\mathrm{ChoCl} /$ citric acid were found very effective for the reaction. For example, $\mathrm{HMF}$ yield was $83 \%$ where the ionic liquid $\mathrm{ChoCl} /$ citric acid was used as the solvent. It was also found that HMF was rather stable in these ionic liquids. In order to improve the HMF yield and selectivity in $\mathrm{ChoCl} /$ citric acid, and to reuse the ionic liquid, ethyl acetate was added as an extracting solvent to extract HMF out of the system, which gave a HMF yield of $86 \%$, about $9 \%$ higher than that in the absence of the extract solvent. The ionic liquids-catalyst mixture was successfully recycled after pouring out the ethyl acetate phase. The most important aspects of this work are, 1) ionic liquids synthesized from biorenewable feedstock, and 2) the reaction performed under continuous reactionextraction fashion. These are two important factors determining the practical potential of a technology in a large scale. Further study from the same group also showed that the system was also appropriate for the direct conversion of inulin to HMF in $64 \%$ yield under mild conditions (Hu et al. 2009).

With the consideration of the toxicity of chromium ion, researchers are devoting to discovering a cheap, non-toxic, easily handled catalysts for the selective conversion of (ligno)cellulose into furans. $\mathrm{SnCl}_{4}$ is a common, cheap, easy handling Lewis acid, and has a much lower toxicity. $\mathrm{Hu}$ and co-workers investigated its catalytic activity in several ionic liquids for the conversion of glucose into HMF. The activity mostly varied with the anions in ionic liquids, and a best result of $61 \%$ yield was obtained in [Emim]BF 4 . It is interesting to mention that although the $\mathrm{Cl}^{-}$is essential for the $\mathrm{Cr}^{2+}$ catalytic system, it does not work well in this system (Hu et al. 2009). Inspired by a catalytic effect on glucose dehydration by lanthanide chlorides in supercritical water, the catalytic effect of lanthanide catalysts on the conversion of glucose into HMF in ionic liquids was investigated (Stahlberg et al. 2010). However, HMF yields were moderate or relatively low (less than 30\%). Germanium (IV) chloride is an environment-friendly Lewis acid. We recently investigated the direct conversion of carbohydrates into HMF in $\left[\mathrm{C}_{4} \mathrm{mim}\right] \mathrm{Cl}$ (Zhang et al. 2010). It was found that monosaccharides D-fructose and D-glucose, disaccharides sucrose and maltose, and even polysaccharides cellulose were successfully converted into HMF with good yields ranging from $30 \%$ to $92 \%$ under mild conditions. Thus, a HMF yield of $92 \%$ was achieved in 5 min in the case of fructose. Interestingly, we noticed that a higher content of water content in the system resulted in a lower HMF yield. However, addition of $5 \AA$ molecular sieves during the dehydration of glucose afforded an increase in HMF yield from $38 \%$ to $48 \%$.

\section{Conclusions and prospects}

Clearly, the conversion of biomass into value added chemicals in ionic liquids is just kicking start, and the complex challenge will certainly require the integration of advanced catalytic and separation technologies. This chapter has sought to highlight the up-to-date progress in 
this area, especially molecular level understanding of the dissolution of biomass in ionic liquids, strategies for the conversion of (ligno)cellulose into fermentable sugars and furans, and related chemicals.

Undoubtedly, many milestone-results have been obtained so far. For example, a remarkable TRS yield of $97 \%$ was obtained for hydrolysis of cellulose in the water system under mild conditions, which should provide cheaper fermentable feedstocks. If the separation of monosaccharides from ionic liquids were realized economically, the cost of the second generation of bioenergy is expected to be reduced significantly. Indeed, there are at least two references about sugar recovery after the hydrolysis of cellulose in ionic liquids. One is to use ion-exclusion chromatography to simultaneously recover the ionic liquids and the sugars from the reaction mixture, and the obtained sugar solution was proved suitable for the production of ethanol by ethanologenic bacterium or yeast (Binder and Raines 2010). Another method is to recover the sugars from ionic liquids by extraction based on the chemical affinity of sugars to boronates such as phenyl boronic acid and naphthalene-2boronic acid (Brennan et al. 2010). It was shown that boronate complexes could extract up to $90 \%$ of mono- and disaccharides from aqueous ionic liquids solutions, pure ionic liquids systems, or hydrolysates of corn stover containing ionic liquids. Both of these methods delivered a solution of fermentable sugars, reduced toxic byproducts, and presented technical approaches to the challenging separation problem in the ionic liquid-based biorefinery. The integration of these processes into the traditional fermentable processes should provide better chances for the production of the second generation of biofuels.

The furans, especially HMF, are regarded as important intermediates bridging the carbohydrate chemistry and petroleum chemistry. For a long time, the direct and efficient conversion of cellulose and glucose into HMF is not successful. With the ionic liquids technology, HMF can now be produced in over $70 \%$ yields directly from cellulose under mild conditions. The continual development of downstream products from furans remains challenging. In the future, efforts should also be paid to the synthesis, structural characterization and properties study of new bioproducts or biofuels from these platform molecules. The increasing end product market will promote the related field developing.

Bearing all of these significant progresses in mind, technological and scientific challenges, however, remain to be addressed, such as, economic synthesis at a large scale, definition of recycling pathways, efficient products/ionic liquids separation, development of new efficient catalysts, production of new value-added chemicals, biodegradation/bioaccumulation studies as well as toxicity and handling considerations of ionic liquids. The future is prosperous, while opportunities always are sided with challenges on the road to industrial applications. Further research in the area of selective breakdown of (ligno)cellulose, or more general speaking, utilization of biomass incorporating ionic liquids technology is expected as below:

1. Development of new catalytic systems for more efficient transformations, such as depolymerization, dehydration, hydrogenolysis, or alcoholysis, of (ligno)cellulose and related materials;

2. Exploitation of novel chemistry of (ligno)cellulose in ionic liquids or ionic liquidcontaining media;

3. Integration of the ionic liquids processes with other chemical or biological processes;

4. Design and preparation of cheaper, greener and process-compatible ionic liquids; 
5. Developing new strategies for ionic liquids recycling and product recovery;

6. Catalytic conversion of lignin into value-added chemicals.

\section{References}

Amarasekara, A. S. and Owereh, O. S. (2009). Hydrolysis and Decomposition of Cellulose in Bronsted Acidic Ionic Liquids under Mild Conditions. Industrial \& Engineering Chemistry Research 48(22): 10152-10155.

Amarasekara, A. S. and Owereh, O. S. (2010). Synthesis of a Sulfonic Acid Functionalized Acidic Ionic Liquid Modified Silica Catalyst and Applications in the Hydrolysis of Cellulose. Catalysis Communications 11(13): 1072-1075.

Alonso, D. M., Bond, J. Q. and Dumesic, J. A. (2010). Catalytic Conversion of Biomass to Biofuels. Green Chemistry, 12(9):1493-1513

Anastas, P. T. and Zimmerman, J. B. (2003). Design through the 12 Principles of Green Engineering. Environmental Science \& Technology 37(5): 94A-101A.

Binder, J. B., Cefali, A. V., Blank, J. J. and Raines, R. T. (2010). Mechanistic Insights on the Conversion of Sugars into 5-Hydroxymethylfurfural. Energy \& Environmental Science 3(6): 765-771.

Binder, J. B. and Raines, R. T. (2009). Simple Chemical Transformation of Lignocellulosic Biomass into Furans for Fuels and Chemicals. Journal of the American Chemical Society 131(5): 1979-1985.

Binder, J. B. and Raines, R. T. (2010). Fermentable Sugars by Chemical Hydrolysis of Biomass. Proceedings of the National Academy of Sciences of the United States of America 107(10): 4516-4521.

Bose, S., Armstrong, D. W. and Petrich, J. W. (2010). Enzyme-Catalyzed Hydrolysis of Cellulose in Ionic Liquids: A Green Approach toward the Production of Biofuels. Journal of Physical Chemistry B 114(24): 8221-8227.

Brennan, T. C. R., Datta, S., Blanch, H. W., Simmons, B. A. and Holmes, B. M. (2010). Recovery of Sugars from Ionic Liquid Biomass Liquor by Solvent Extraction. Bioenergy Research 3(2): 123-133.

Cheng, S. M. and Zhu, S. D. (2009). Lignocellulosic Feedstock Biorefinery-the Future of the Chemical and Energy Industry. Bioresources 4(2): 456-457.

Chheda, J. N., Huber, G. W. and Dumesic, J. A. (2007). Liquid-Phase Catalytic Processing of Biomass-Derived Oxygenated Hydrocarbons to Fuels and Chemicals. Angewandte Chemie-International Edition 46(38): 7164-7183.

Chidambaram, M. and Bell, A. T. (2010). A Two-Step Approach for the Catalytic Conversion of Glucose to 2,5-Dimethylfuran in Ionic Liquids. Green Chemistry 12(7): 1253-1262.

Coleman, D. and Gathergood, N. (2010). Biodegradation Studies of Ionic Liquids. Chemical Society Reviews 39(2): 600-637.

Corma, A., Iborra, S. and Velty, A. (2007). Chemical Routes for the Transformation of Biomass into Chemicals. Chemical Reviews 107(6): 2411-2502.

Farber, G. K., Glasfeld, A., Tiraby, G., Ringe, D. and Petsko, G. A. (1989). Crystallographic Studies of the Mechanism of Xylose Isomerase. Biochemistry 28(18): 7289-7297.

Fukaya, Y., Sugimoto, A. and Ohno, H. (2006). Superior Solubility of Polysaccharides in Low Viscosity, Polar, and Halogen-Free 1,3-Dialkylimidazolium Formates. Biomacromolecules 7(12): 3295-3297. 
Gallezot, P. (2008). Catalytic Conversion of Biomass: Challenges and Issues. ChemSusChem 1(8-9): 734-737.

Harris, D. W. and Feather, M. S. (1974). Intramolecular C-2- C-1 Hydrogen TransferReactions During Conversion of Aldoses to 2-Furaldehydes. Journal of Organic Chemistry 39(5): 724-725.

Harris, D. W. and Feather, M. S. (1975). Studies on Mechanism of Interconversion of DGlucose, D-Mannose, and D-Fructose in Acid Solution. Journal of the American Chemical Society 97(1): 178-182.

Hu, S. Q., Zhang, Z. F., Song, J. L., Zhou, Y. X. and Han, B. X. (2009). Efficient Conversion of Glucose into 5-Hydroxymethylfurfural Catalyzed by a Common Lewis Acid Sncl in an Ionic Liquid. Green Chemistry 11(11): 1746-1749.

Hu, S. Q., Zhang, Z. F., Zhou, Y. X., Song, J. L., Fan, H. L. and Han, B. X. (2009). Direct Conversion of Inulin to 5-Hydroxymethylfurfural in Biorenewable Ionic Liquids. Green Chemistry 11(6): 873-877.

Hu, S. Q., Zhang, Z. F., Zhou, Y. X., Han, B. X., Fan, H. L., Li, W. J., Song, J. L. and Xie, Y. (2008). Conversion of Fructose to 5-Hydroxymethylfurfural Using Ionic Liquids Prepared from Renewable Materials. Green Chemistry 10(12): 1280-1283.

Huber, G. W., Iborra, S. and Corma, A. (2006). Synthesis of Transportation Fuels from Biomass: Chemistry, Catalysts, and Engineering. Chemical Reviews 106(9): 40444098.

Ignatyev, I. A., Van Doorslaer, C., Mertens, P. G. N., Binnemans, K. and de Vos, D. E. (2010). Reductive Splitting of Cellulose in the Ionic Liquid 1-Butyl-3-Methylimidazolium Chloride. ChemSusChem 3(1): 91-96.

Ignatyev, I. A., Mertens, P. G. N., Van Doorslaer, C., Binnemans, K. and de Vos, D. E. (2010). Cellulose Conversion into Alkylglycosides in the Ionic Liquid 1-Butyl-3Methylimidazolium Chloride. Green Chemistry 12(10): 1790-1795.

Johnson, B. F. G. (2003). Nanoparticles in Catalysis. Topics in Catalysis 24(1-4): 147-159.

Kamiya, N., Matsushita, Y., Hanaki, M., Nakashima, K., Narita, M., Goto, M. and Takahashi, H. (2008). Enzymatic in Situ Saccharification of Cellulose in Aqueous-Ionic Liquid Media. Biotechnology Letters 30(6): 1037-1040.

Kamm, B. (2007). Production of Platform Chemicals and Synthesis Gas from Biomass. Angewandte Chemie-International Edition 46(27): 5056-5058.

Kilpelainen, I., Xie, H., King, A., Granstrom, M., Heikkinen, S. and Argyropoulos, D. S. (2007). Dissolution of Wood in Ionic Liquids. Journal of Agricultural and Food Chemistry 55: 9142-9148.

Kim, S. J., Dwiatmoko, A. A., Choi, J. W., Suh, Y. W., Suh, D. J. and Oh, M. (2010). Cellulose Pretreatment with 1-n-Butyl-3-Methylimidazolium Chloride for Solid AcidCatalyzed Hydrolysis. Bioresource Technology 101(21): 8273-8279.

Li, B., Filpponen, I. and Argyropoulos, D. S. (2010). Acidolysis of Wood in Ionic Liquids. Industrial \& Engineering Chemistry Research 49(7): 3126-3136.

Li, C. Z. (2008). Application of Ionic Liquids in Biomass Conversion and Friedel-Crafts Acylation Reactions. Ph.D. Thesis, Dalian Institute of Chemical Physics, CAS.

Li, C. Z., Wang, Q. and Zhao, Z. K. (2008). Acid in Ionic Liquid: An Efficient System for Hydrolysis of Lignocellulose. Green Chemistry 10(2): 177-182. 
Li, C. Z., Zhang, Z. H. and Zhao, Z. K. (2009). Direct Conversion of Glucose and Cellulose to 5 -Hydroxymethylfurfural in Ionic Liquid under Microwave Irradiation. Tetrahedron Letters 50(38): 5403-5405.

Li, C. Z. and Zhao, Z. K. (2007). Efficient Acid-Catalyzed Hydrolysis of Cellulose in Ionic Liquid. Advanced Synthesis \& Catalysis 349: 1847-1850.

Li, Q., He, Y. C., Xian, M., Jun, G., Xu, X., Yang, J. M. and Li, L. Z. (2009). Improving Enzymatic Hydrolysis of Wheat Straw Using Ionic Liquid 1-Ethyl-3-Methyl Imidazolium Diethyl Phosphate Pretreatment. Bioresource Technology 100(14): 3570-3575.

Liu, H. B., Sale, K. L., Holmes, B. M., Simmons, B. A. and Singh, S. (2010). Understanding the Interactions of Cellulose with Ionic Liquids: A Molecular Dynamics Study. Journal of Physical Chemistry B 114(12): 4293-4301.

Liu, L. Y. and Chen, H. Z. (2006). Enzymatic Hydrolysis of Cellulose Materials Treated with Ionic Liquid Bmim Cl. Chinese Science Bulletin 51(20): 2432-2436.

MacFarlane, D. R., Pringle, J. M., Johansson, K. M., Forsyth, S. A. and Forsyth, M. (2006). Lewis Base Ionic Liquids. Chemical Communications (18): 1905-1917.

Moniruzzaman, M., Nakashima, K., Kamiya, N. and Goto, M. (2010). Recent Advances of Enzymatic Reactions in Ionic Liquids. Biochemical Engineering Journal 48(3): 295314.

Ong, Y. K. and Bhatia, S. (2010). The Current Status and Perspectives of Biofuel Production Via Catalytic Cracking of Edible and Non-Edible Oils. Energy 35(1): 111-119.

Pidko, E. A., Degirmenci, V., van Santen, R. A. and Hensen, E. J. M. (2010). Glucose Activation by Transient $\mathrm{Cr}^{2+}$ Dimers. Angewandte Chemie-International Edition 49(14): 2530-2534.

Pinkert, A., Marsh, K. N., Pang, S. S. and Staiger, M. P. (2009). Ionic Liquids and Their Interaction with Cellulose. Chemical Reviews 109(12): 6712-6728.

Ragauskas, A. J., Williams, C. K., Davison, B. H., Britovsek, G., Cairney, J., Eckert, C. A., Frederick, W. J., Hallett, J. P., Leak, D. J., Liotta, C. L., Mielenz, J. R., Murphy, R., Templer, R. and Tschaplinski, T. (2006). The Path Forward for Biofuels and Biomaterials. Science 311(5760): 484-489.

Remsing, R. C., Liu, Z. W., Sergeyev, I. and Moyna, G. (2008). Solvation and Aggregation of N,N'-Dialkylimidazolium Ionic Liquids: A Multinuclear NMR Spectroscopy and Molecular Dynamics Simulation Study. Journal of Physical Chemistry B 112(25): 7363-7369.

Remsing, R. C., Swatloski, R. P., Rogers, R. D. and Moyna, G. (2006). Mechanism of Cellulose Dissolution in the Ionic Liquid 1-N-Butyl-3-Methylimidazolium Chloride: A C-13 and Cl-35/37 NMR Relaxation Study on Model Systems. Chemical Communications (12): 1271-1273.

Remsing, R. C., Wildin, J. L., Rapp, A. L. and Moyna, G. (2007). Hydrogen Bonds in Ionic Liquids Revisited: Cl-35/37 NMR Studies of Deuterium Isotope Effects in 1-NButyl-3-Methylimidazolium Chloride. Journal of Physical Chemistry B 111(40): 11619-11621.

Rinaldi, R., Palkovits, R. and Schuth, F. (2008). Depolymerization of Cellulose Using Solid Catalysts in Ionic Liquids. Angewandte Chemie-International Edition 47(42): 80478050 . 
Rinaldi, R., Meine, N., vom Stein, J., Palkovits, R. and Schuth, F. (2010). Which Controls the Depolymerization of Cellulose in Ionic Liquids: The Solid Acid Catalyst or Cellulose? ChemSusChem 3(2): 266-276.

Rogers, R. D. and Seddon, K. R. (2003). Ionic Liquids - Solvents of the Future? Science 302(5646): 792-793.

Stahlberg, T., Sorensen, M. G. and Riisager, A. (2010). Direct Conversion of Glucose to 5(Hydroxymethyl)furfural in Ionic Liquids with Lanthanide Catalysts. Green Chemistry 12(2): 321-325.

Stephanopoulos, G. (2007). Challenges in Engineering Microbes for Biofuels Production. Science 315(5813): 801-804.

Su, Y., Brown, H. M., Huang, X. W., Zhou, X. D., Amonette, J. E. and Zhang, Z. C. (2009). Single-Step Conversion of Cellulose to 5-Hydroxymethylfurfural (HMF), a Versatile Platform Chemical. Applied Catalysis A-General 361(1-2): 117-122.

Swatloski, R. P., Spear, S. K., Holbrey, J. D. and Rogers, R. D. (2002). Dissolution of Cellose with Ionic Liquids. Journal of the American Chemical Society 124(18): 4974-4975.

Thi, P. T. P., Cho, C. W. and Yun, Y. S. (2010). Environmental Fate and Toxicity of Ionic Liquids: A Review. Water Research 44(2): 352-372.

Vanoye, L., Fanselow, M., Holbrey, J. D., Atkins, M. P. and Seddon, K. R. (2009). Kinetic Model for the Hydrolysis of Lignocellulosic Biomass in the Ionic Liquid, 1-Ethyl-3Methyl-Imidazolium Chloride. Green Chemistry 11(3): 390-396.

Villandier, N. and Corma, A. (2010). One Pot Catalytic Conversion of Cellulose into Biodegradable Surfactants. Chemical Communications 46(24): 4408-4410.

Werpy, T., Petersen, G. Eds. (2004). Top Value Added Chemicals from Biomass, Report: Doe/Go-102004-1992;. U.S. Department of Energy.

Xie, H., Kilpeläinen, I., King, A., W., T., Järvi, P. and Argyropoulos, D. S., (2009). Opportunities with Dissolved Wood. Cellulose Solvents: For Analysis, Shaping and Chemical Modification. Liebert, T., et al., ACS Symposium Series, 2009, Chapter 19, 343-363.

Xie, H., King, A., Kilpelainen, I., Granstrom, M. and Argyropoulos, D. S. (2007). Thorough Chemical Modification of Wood-Based Lignocellulosic Materials in Ionic Liquids. Biomacromolecules 8(12): 3740-3748.

Yang, F., Li, L. Z., Li, Q., Tan, W. G., Liu, W. and Xian, M. (2010). Enhancement of Enzymatic in Situ Saccharification of Cellulose in Aqueous-Ionic Liquid Media by Ultrasonic Intensification. Carbohydrate Polymers 81(2): 311-316.

Youngs, T. G. A., Hardacre, C. and Holbrey, J. D. (2007). Glucose Solvation by the Ionic Liquid 1,3-Dimethylimidazolium Chloride: A Simulation Study. Journal of Physical Chemistry B 111(49): 13765-13774.

Zakrzewska, M. E., Bogel-Lukasik, E. and Bogel-Lukasik, R. (2010). Solubility of Carbohydrates in Ionic Liquids. Energy \& Fuels 24: 737-745.

Zavrel, M., Bross, D., Funke, M., Buchs, J. and Spiess, A. C. (2009). High-Throughput Screening for Ionic Liquids Dissolving (Ligno-)Cellulose. Bioresource Technology 100(9): 2580-2587.

Zhang, Y. T., Du, H. B., Qian, X. H. and Chen, E. Y. X. (2010). Ionic Liquid-Water Mixtures: Enhanced Kw for Efficient Cellulosic Biomass Conversion. Energy \& Fuels 24: 24102417. 
Zhang, Z. H., Wang, Q., Xie, H. B., Dong, K., Liu, W. J. and Zhao, Z. K. (2010). Catalytic Conversion of Carbohydrates into 5-Hydroxymethylfurfural by Germanium (IV) Chloride in Ionic Liquids. ChemSusChem, DOI: 10.1002/cssc.201000279.

Zhang, Z. H. and Zhao, Z. K. (2010). Microwave-Assisted Conversion of Lignocellulosic Biomass into Furans in Ionic Liquid. Bioresource Technology 101(3): 1111-1114.

Zhao, H. (2010). Methods for Stabilizing and Activating Enzymes in Ionic Liquids - a Review. Journal of Chemical Technology and Biotechnology 85(7): 891-907.

Zhao, H. B., Holladay, J. E., Brown, H. and Zhang, Z. C. (2007). Metal Chlorides in Ionic Liquid Solvents Convert Sugars to 5-Hydroxymethylfurfural. Science 316(5831): 1597-1600.

Zhu, S. D., Wu, Y. X., Chen, Q. M., Yu, Z. N., Wang, C. W., Jin, S. W., Ding, Y. G. and Wu, G. (2006). Dissolution of Cellulose with Ionic Liquids and Its Application: A MiniReview. Green Chemistry 8(4): 325-327.

Zhu, Y. H., Kong, Z. N., Stubbs, L. P., Lin, H., Shen, S. C., Anslyn, E. V. and Maguire, J. A. (2010). Conversion of Cellulose to Hexitols Catalyzed by Ionic Liquid-Stabilized Ruthenium Nanoparticles and a Reversible Binding Agent. ChemSusChem 3(1): 6770 . 


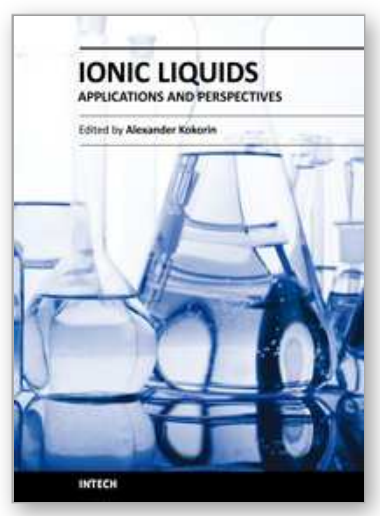

\author{
Ionic Liquids: Applications and Perspectives \\ Edited by Prof. Alexander Kokorin
}

ISBN 978-953-307-248-7

Hard cover, 674 pages

Publisher InTech

Published online 21, February, 2011

Published in print edition February, 2011

This book is the second in the series of publications in this field by this publisher, and contains a number of latest research developments on ionic liquids (ILs). This promising new area has received a lot of attention during the last 20 years. Readers will find 30 chapters collected in 6 sections on recent applications of ILs in polymer sciences, material chemistry, catalysis, nanotechnology, biotechnology and electrochemical applications. The authors of each chapter are scientists and technologists from different countries with strong expertise in their respective fields. You will be able to perceive a trend analysis and examine recent developments in different areas of ILs chemistry and technologies. The book should help in systematization of knowledges in ILs science, creation of new approaches in this field and further promotion of ILs technologies for the future.

\title{
How to reference
}

In order to correctly reference this scholarly work, feel free to copy and paste the following:

Haibo Xie and Zongbao K. Zhao (2011). Selective Breakdown of (Ligno)cellulose in lonic Liquids, lonic Liquids: Applications and Perspectives, Prof. Alexander Kokorin (Ed.), ISBN: 978-953-307-248-7, InTech, Available from: http://www.intechopen.com/books/ionic-liquids-applications-and-perspectives/selective-breakdown-ofligno-cellulose-in-ionic-liquids

\section{INTECH}

open science | open minds

\author{
InTech Europe \\ University Campus STeP Ri \\ Slavka Krautzeka 83/A \\ 51000 Rijeka, Croatia \\ Phone: +385 (51) 770447 \\ Fax: +385 (51) 686166 \\ www.intechopen.com
}

\author{
InTech China \\ Unit 405, Office Block, Hotel Equatorial Shanghai \\ No.65, Yan An Road (West), Shanghai, 200040, China \\ 中国上海市延安西路65号上海国际贵都大饭店办公楼405单元 \\ Phone: +86-21-62489820 \\ Fax: +86-21-62489821
}


(C) 2011 The Author(s). Licensee IntechOpen. This chapter is distributed under the terms of the Creative Commons Attribution-NonCommercialShareAlike-3.0 License, which permits use, distribution and reproduction for non-commercial purposes, provided the original is properly cited and derivative works building on this content are distributed under the same license. 